\title{
Synthesis and Characterization of a New Ternary Imide $-\mathrm{Li}_{2} \mathrm{Ca}(\mathrm{NH})_{2}$
}

Guotao Wu, ${ }^{1}$ Zhitao Xiong, ${ }^{1}$ Tao Liu, ${ }^{1}$ Yongfeng Liu, ${ }^{1}$ Jianjiang Hu, ${ }^{1}$ Ping Chen, ${ }^{* 1,2}$ Yuanping Feng, ${ }^{1}$ Andrew T. S. Wee ${ }^{1}$

${ }^{1}$ Department of Physics, National University of Singapore, 10 Kent Ridge Crescent, Singapore 117542

${ }^{2}$ Department of Chemistry, National University of Singapore, 10 Kent Ridge Crescent, Singapore 117543

*Correspondence author, Fax: +65-67776126; Tel: +65-65165100; E-mail: phychenp@nus.edu.sg

\section{Supporting Information}

Theoretical investigations on $\mathrm{Li}_{2} \mathrm{Ca}(\mathrm{NH})_{2}$ were preformed using first-principle calculations based on the density functional theory (DFT) and the pseudopotential-planewave method. ${ }^{1 \mathrm{~S}}$ The projector augmented wave potentials ${ }^{2 \mathrm{~S}}$ were used to describe the electron-ion interaction, and the generalized gradient approximation (GGA) due to Perdew, Burke and Ernzerhof $(\mathrm{PBE})^{3 \mathrm{~S}}$ was used for exchangecorrelation functional. A plane-wave cutoff corresponding to an energy of $320 \mathrm{eV}$ was used in our calculations. For a unit cell containing one formula unit of $\mathrm{Li}_{2} \mathrm{Ca}(\mathrm{NH})_{2}$, a k-point mesh of $8 \times 8 \times 4$ was used.

It is assumed that $\mathrm{H}$ atoms should be restricted somewhere in the system host consisting of $\mathrm{N}, \mathrm{Ca}$ and $\mathrm{Li}$ atoms, and therefore $\mathrm{H}$ atoms have little effect on the system host. Lattice constants are derived from the XRD experimental values $\left(a=b=3.5664 \AA\right.$ and $c=5.9540 \AA, \alpha=\beta=90^{\circ}$ and $\left.\gamma=120^{\circ}\right)$. The $\mathrm{N}, \mathrm{Ca}$ and $\mathrm{Li}$ are in the same positions as those suggested by our Retvield refinement results. Li1( 0.3333 , $0.6667,0.8841), \quad \mathrm{Li} 2(0.6667,0.3333, \quad 0.11591), \quad \mathrm{Ca}(0,0,0.5), \quad \mathrm{N} 1(0.3333,0.6667,0.2565), \quad$ and 
$\mathrm{N} 2(0.6667,0.3333,0.7435)$ are included in a conventional cell. The initial site of each $\mathrm{H}$ is randomly selected around each $\mathrm{N}$. Only the $\mathrm{H}$ atom coordinates are relaxed. The relaxed $\mathrm{H}$ atom coordinates are essentially the same as those special sites represented by $2 \mathrm{~d}$, 6i sites of the space group P-3m1, as show in the Table 1S. Total energies of structures with $\mathrm{H}$ atoms located in different sites are listed in Table 2S. It can be seen in Table $1 \mathrm{~S}$ that the $\mathrm{N}-\mathrm{H}$ vector orients towards the middle point or center of adjacent lithium sites or adjacent $\mathrm{Ca}$ sites. When each $\mathrm{H}$ occupies one of Site-III sites around each $\mathrm{N}$, the $\mathrm{Li}_{2} \mathrm{Ca}(\mathrm{NH})_{2}$ structure has the lowest total energy, in which the $\mathrm{N}-\mathrm{H}$ vector orients towards the middle point of two adjacent lithium sites ( $\mathrm{Li}-\mathrm{Li}$ distance $3.566 \AA$ ). The Site-III sites correspond to $6 \mathrm{i}$ equivalent sites of the space group P-3m1. Unfortunately, H atoms can not fully occupy equivalent positions of $6 \mathrm{i}$ sites according to the composition of $\mathrm{Li}_{2} \mathrm{Ca}(\mathrm{NH})_{2}$. In general, the $\mathrm{H}$ atom in lithium imide is delocalized over several equivalent sites around each $\mathrm{N}^{4 \mathrm{~S}}$. Similarly, it is likely that each $\mathrm{H}$ in $\mathrm{Li}_{2} \mathrm{Ca}(\mathrm{NH})_{2}$ is delocalized over the $6 \mathrm{i}$ equivalent sites around each $\mathrm{N}$ to satisfy the crystallographic symmetry.

\section{References for Supporting Information}

(1S) G. Kresse and J. Furthmuller, Comput. Mater. Sci. 1996, 6, 15; Phys. Rev. B 1996, 54, 11169

(2S) P. E. Blochl, Phys. Rev. B 1994, 50, 17953; G. Kresse, and J. Joubert, Phys. Rev. B 1999, 59, 1758

(3S) J. P. Perdew, K. Burke, M. Ernzerhof, Phys. Rev. Lett. 1996, 77, 3865

(4S) C.J. Zhang, M. Dyer, A. Alavi, J. Phys. Chem. B 2005, 109, 22089 
Table 1S. Stable H sites in the system host consist of N, Ca and Li atoms

\begin{tabular}{|c|c|c|}
\hline \multicolumn{2}{|c|}{ The relaxed $\mathrm{H}$ atom coordinates } & \multirow{2}{*}{$\begin{array}{l}\text { Equivalent sites in S.G P-3m1 } \\
\mathrm{N}-\mathrm{H} \text { vector orientation }\end{array}$} \\
\hline Near N1 atom & Near N2 atom & \\
\hline I) $(0.3333,0.6667,0.4307)$ & $(0.6667,0.3333,0.5693)$ & $\begin{array}{l}2 \mathrm{~d} \text {, the center of } \\
\text { adjacent } \mathrm{Ca} \text { siangle } \\
\text { distance } 3.566 \AA \text { ) }\end{array}$ \\
\hline II) $(0.3333,0.6667,0.0909)$ & $(0.6667,0.3333,0.9091)$ & $\begin{array}{l}2 \mathrm{~d} \text {, the center of triangle } \\
\text { adjacent } \mathrm{Li} \text { sites ( } \mathrm{Li}-\mathrm{Li} \text { distance } \\
3.566 \AA \text { ) }\end{array}$ \\
\hline III) $(0.1838,0.8162,0.1723)$ & $(0.8162,0.1838,0.8277)$ & $6 \mathrm{i}$, the middle point of two \\
\hline$(0.6324,0.8162,0.1723)$ & $(0.3676,0.1838,0.8277)$ & $3.566 \AA)$ \\
\hline$(0.1838,0.3676,0.1723)$ & $(0.8162,0.6324,0.8277)$ & \\
\hline IV) $(0.4278,0.5722,0.1179)$ & $(0.5722,0.4278,0.8821)$ & $6 \mathrm{i}$, the middle point of two \\
\hline$(0.1444,0.5722,0.1179)$ & $(0.8556,0.4278,0.8821)$ & $2.479 \AA)$ \\
\hline$(0.4278,0.8556,0.1179)$ & $(0.5722,0.1444,0.8821)$ & \\
\hline V) $(0.4875,0.5125,0.3243)$ & $(0.5125,0.4875,0.6757)$ & $6 \mathrm{i}$, the middle point of two \\
\hline$(0.0250,0.5125,0.3243)$ & $(0.9750,0.4875,0.6757)$ & distance $3.566 \AA$ ) \\
\hline$(0.4875,0.9750,0.3243)$ & $(0.5125,0.0250,0.6757)$ & \\
\hline
\end{tabular}


Table 2S. Total energies from DFT calculations for the system host with $\mathrm{H}$ atoms at various sites

\begin{tabular}{llll}
\hline \multicolumn{2}{l}{ The relaxed H atom coordinates } & Symmetry & Total Energy (eV) \\
\hline H1 atom near N1 atom & H2 atom near N2 atom & & \\
Site I & Site I & C_2h & -32.486 \\
Site II & Site II & C_2h & -30.897 \\
Site III & Site III & C1 & -33.094 \\
Site IV & Site IV & C1 & -31.868 \\
Site V & Site V & C1 & -32.577 \\
Site I & Site II & C_1h & -31.734 \\
Site III & Site V & C1 & -32.841 \\
\hline
\end{tabular}

